\title{
PEMIKIRAN ABDULKARIM SOROUSH TENTANG PERSOALAN OTORITAS KEBENARAN AGAMA
}

\author{
Badarussyamsi \\ IAIN Sulthan Thaha Saifuddin Jambi, Indonesia \\ E-mail: badarussyamsi76@gmail.com
}

\begin{abstract}
This article discusses the thought of Abdulkarim Soroush on the relation between the truth claim of religious understanding and the emergence of religious authoritarianism. Truth claim can raise the tyranny of religion when there is an attempt at the ideologization of a religious understanding to political and power sphere. Some questions to be answered here include: why does religious truth claim emerge, and how does Soroush deconstruct religious truth claim? Why does Soroush reject the paradigm of religious ideologization, and how does he promote the democratization of the relation between religion and politics? This article reveals that religious truth claim emerge due to the absence of consciousness to distinguish between religious understanding which is temporal and profan and the very religion which is eternal and sacred. Attempts at ideologizing religion represent the lack of consciousness to distinguish between religion and politics, as this lack can degrade the divine value of religion to its worldly and human character. The ideologization of religion can result in tyranny in the name of religion, and accordingly give the monopoly of power to a certain religious understanding while rejecting others.
\end{abstract}

Keywords: Religion; religious understanding; pluralism; authoritarianism..

\section{Pendahuluan}

Ajaran Tuhan diturunkan kepada manusia melalui para Nabi dan Rasul pilihan-Nya. Di tangan para Nabi dan Rasul, otoritas kebenaran agama merupakan hal yang tidak dapat dibantah lagi karena pemahaman dan penjelasan Nabi dan Rasul akan firman Tuhan dituntun langsung oleh Tuhan. Sepeninggal Nabi dan Rasul, pemahaman, penafsiran, dan penjelasan tentang agama menjadi tugas para murid maupun sahabat Rasul yang tidak dituntun langsung oleh Tuhan. Pemahaman dan penafsiran keagamaan mereka menjadi relatif 
dan dipengaruhi oleh tingkat kesalehan, keilmuwan, ketakwaan, dan kedekatan dengan Rasul. Pada masa empat sahabat awal, Abû Bakr dan 'Umar b. al-Khațâb hampir tidak meninggalkan persoalan terkait pemahaman keagamaan karena mereka adalah orang-orang dekat Rasul yang sekaligus terkenal dengan ketakwaannya. Hal ini tampak sangat berbeda dengan dua khalifah sesudahnya yakni masa 'Uthmân b. 'Affân dan 'Alî b. Abî Țâlib. Khususnya pada masa 'Alî, pertikaian politik terkait dengan legalitas pemimpin agama dan tafsiran tentang "dosa besar" sebagai ukuran bagi sebutan "kafir" semakin memperjelas bahwa umat Islam telah ditimpa relativitas kebenaran interpretasi keagamaan.

Permasalahan yang akan dibahas dalam artikel ini berkisar pada munculnya klaim kebenaran pemahaman keagamaan dan bagaimana klaim tersebut dapat mengakibatkan terjadinya otoritarianisme pemahaman keagamaan. Tidak jarang sebuah klaim kebenaran interpretasi keagamaan mengarahkan sang pemilik interpretasi untuk melakukan tirani atas nama agama. Bagaimana Soroush menghubungkan pluralitas pemikiran keagamaan dan perlunya penegakan nilai-nilai demokrasi dalam menghadapi ancaman otoritarianisme keagamaan ini? Bagaimana teori Soroush yang terkenal yakni the contraction and expansion of religious interpretation diarahkan untuk membendung otoritarianisme dan tirani atas nama agama?

\section{Otoritas Kebenaran Agama}

Abdulkarim Soroush merupakan pemikir Islam dari Iran yang dapat digolongkan sebagai tokoh anti-kemapanan pemahaman keagamaan. Pemahaman keagamaan tidak dapat dijadikan sebagai kebenaran absolut karena semua itu hanya merupakan hasil pemikiran manusia. Forough Jahanbakhsh menggarisbawahi pemikiran Soroush ke dalam lima poin, antara lain: (1) pembedaan agama dan pemikiran keagamaan, (2) agama itu bersifat ketuhanan, kekal, tahan, dan sakral, (3) pemahaman keagamaan dan pengetahuan agama tidak sakral, (4) pemahaman agama dipengaruhi oleh pengetahuan manusia, dan (5) pengetahuan agama itu berubah-ubah dan terikat waktu. ${ }^{1}$

Absolutisme pemikiran keagamaan merupakan sasaran dari pemikiran Soroush. Ia memang mempertanyakan kembali absolutisme dan rigiditas praktik-praktik keagamaan. Soroush sedang mengonstruksi sebuah kondisi sebagai dasar bagi perubahan politik

${ }^{1}$ Forough Jahanbakhsh, Islam, Democracy, and Religious Modernism in Iran 1953-2000: from Bazargan to Soroush (Leiden: Brill, 2001), 148. 
sebagaimana pembaruan keagamaan. ${ }^{2}$ Setiap orang memiliki hak untuk berusaha memahami agama untuk direalisasikannya, dan tentu saja terdapat perbedaan pada masing-masing pemikiran terhadap agama. Semakin tinggi kualitas keilmuwan seseorang tentu saja akan menghasilkan bentuk pemahaman keagamaan yang lebih baik. Dengan demikian, pemikiran keagamaan bisa bervariasi dan bahkan menarik hati. Yang pasti semua itu bukan agama, karena semuanya bersifat manusiawi.

Soroush menjelaskan bahwa agama turun atas kehendak Tuhan, tetapi memahami dan berupaya merealisir agama terserah pada kita. Pada titik inilah ilmu agama lahir, yang bersifat sepenuhnya manusiawi dan bergantung pada penguasaan pengetahuan manusia. Orang-orang yang mencari unsur-unsur yang konstan dan yang varian dalam agama hendaknya mengetahui bahwa perbedaan antara keduanya dan ketentuan atas perwujudannya adalah bagian dari wilayah "ilmu agama" dan—dengan demikian—keduanya menuruti interpretasi tertentu terhadap agama. Ketentuan atas unsur-unsur yang konstan dan yang varian tidak akan diperoleh sebelum pemahaman agama, melainkan setelahnya. ${ }^{3}$ Pemahaman seperti ini akan mengarahkan pada penolakan absolutisme pemahaman dan pengetahuan agama di satu sisi. Sementara di sisi lain, hal ini mendorong terbangunnya pola pikir plural dalam memahami agama, di mana pengetahuan dan pemahaman agama masing-masing orang dapat memperoleh penghargaan.

Bagi Soroush sebagaimana dikutip Valla Vakili, meskipun agama tidak berubah, akan tetapi pemahaman dan pengetahuan manusia tentang agama berubah. Pengetahuan agama hanya satu dari sekian cabang pengetahuan manusia. Ia tidak dituhankan oleh sifat ketuhanan agama, dan ia tidak boleh dirancukan dengan agama itu sendiri. Pengetahuan agama dihasilkan oleh para cendekia yang melibatkan diri dalam pembelajaran inti naskah-naskah Islam yang tidak akan pernah berubah-al-Qur'ân, hadîth, dan ajaran Imamimam Shî‘ ah. Para cendekia tersebut menafsirkan naskah-naskah itu secara berlainan, tergantung dari metode mereka, yang mencakup,

2 Robin Wright, "Iran's Greatest Political Challenge", World Policy Journal, Vol. 14, No. 1 (1997), 67.

3 Abdolkarim Soroush, Reason, Freedom, and Democracy in Islam Essential Writings of 'Abdolkarim Soroush (Oxford: Oxford University Press, 2000), 31-32. 
misalnya, dari aturan tata bahasa Arab ke logika inferensial, dari filosofi Aristoteles ke hermeneutika kontemporer. ${ }^{4}$

Pengetahuan agama berubah dan berevolusi sepanjang waktu, karena pemahaman yang lebih komprehensif akan menggantikan pemahaman yang lebih terbatas yang muncul lebih awal. Tetapi seluruh penafsiran itu dibatasi oleh zaman kapan seorang cendekia keagamaan hidup dan oleh tingkat kemajuan pengetahuan manusia umumnya dan studi agama khususnya pada zaman itu. Selain itu, mempelajari al-Qur'ân tanpa memperkirakan hal-hal di luar al-Qur'ân adalah tidak mungkin. Perkiraan-perkiraan ini, yang ditentukan oleh pandangan dunia intelektual seorang cendekia (pemahaman tentang ilmu pengetahuan manusia lainnya), memastikan bahwa setiap pemahaman keagamaan terikat oleh waktu karena pengetahuan keagamaan tercipta melalui penerapan "pengetahuan hari ini" dalam studi naskah-naskah keagamaan inti. ${ }^{5}$

Soroush menegaskan bahwa hanya agama yang tidak akan berubah sedangkan pemahaman agama, penafsiran agama, dan ilmu agama akan berubah sesuai dengan waktu. Sifat "perubahan" yang tidak dapat dielakkan oleh pemahaman dan penafsiran agama ini yang diarahkan Soroush untuk menghalangi lahirnya klaim otoritas kebenaran di antara pemahaman dan penafsiran agama yang ada. Hanya agama yang memiliki otoritas kebenaran mutlak, sedangkan pemahaman dan penafsiran agama tidak memiliki kebenaran mutlak dan absolut. Soroush menegaskan bahwa di mana pun yang kita hadapi adalah ilmu agama yang mengamati dan memahami agama, tetapi itu bukan agama. Ketentuan semacam ini mencakup semua cabang ilmu pengetahuan manusia. ${ }^{6}$

Penolakan atas klaim otoritas kebenaran oleh sebuah pemahaman dan penafsiran agama mengarahkan Soroush untuk memperbesar porsi paradigma pluralisme dalam pemikirannya. Menurut Nacim PakShiraz, dalam memahami Islam Soroush menggunakan pendekatan pluralistik atas interpretasi atas Islam. Dalam pidatonya yang disampaikan pada Pusat Studi Demokrasi London pada November 2006, Soroush menegaskan bahwa Islam tidak lain adalah rangkaian tafsiran yang secara intrinsik bersifat plural. Mereka yang telah

4 Valla Vakili, "Abdolkarim Soroush and Critical Discourse in Iran", dalam John L. Esposito and John O. Voll, Makers of Contemporary Islam (New York: Oxford University Press, 2001), 153-154.

${ }^{5}$ Ibid., 154.

${ }^{6}$ Soroush, Reason, 32. 
mendasarkan kekuasaannya pada penafsiran Islam tertentu, enggan untuk mengizinkan penafsiran lain dan menolak mereka sebagai sebuah bid'ah. Keragaman penafsiran-walaupun demikian-tidak terelakkan dan dia berpendapat bahwa para ulama harus terlibat dalam aspek Islam ini. Semenjak tidak adanya penafsiran yang "benar" seseorang dapat mengoreksi dan memodifikasi keberadaan satu penafsiran, tetapi hal ini kemudian secara logika tidak mungkin dipaksakan sebagai penafsiran yang paling baik. Sebagaimana Soroush yang mengajukan pluralitas "jalan yang benar" daripada "satu jalan yang benar". 7

Pemahaman dan penafsiran atas agama dapat dilakukan oleh siapa saja, tanpa terbatas atau harus dimonopoli oleh kalangan ulama tertentu, sepanjang dapat dipertanggungjawabkan secara keilmuwan dan kualitas penafsiran tersebut. Wright yang mencoba menilai Soroush menyatakan bahwa interpretasi agama tidak terbatas dan menjadi monopoli dari para ulama. Pemahaman mungkin lebih dimiliki oleh kaum terpelajar daripada yang lain, tetapi tidak ada interpretasi yang dengan sendirinya lebih otoritatif dari yang lainnya. ${ }^{8}$ Kesadaran bahwa setiap produk pemikiran keagamaan merupakan upaya merealisir agama dalam kehidupan sehari-hari menghasilkan sebuah konsekuensi bahwa agama seolah-olah bisa dibawa oleh siapapun dan dari latar belakang apapun. Sampai di sini penting untuk diwaspadai bahwa jangan sampai agama dijadikan kendaraan bagi pemenuhan kepentingan manusia. Sebaliknya, manusia yang harus terus berupaya untuk sampai pada apa yang diinginkan oleh Tuhan melalui ajarannya meskipun—sekali lagi—kebenaran absolut tetap ada di tangan Tuhan.

Musibah dari adanya klaim otoritas kebenaran sering digambarkan oleh Soroush sebagai perbudakan agama oleh para penafsir agama. Dalam konteks ini Soroush melontarkan pertanyaan-pertanyaan sangat mendasar; mengapa agama yang mestinya menjadi tuan kebudayaan yang berkuasa justru menjadi budak mereka? Mengapa kaum revivalis menyeru supaya agama dibersihkan dan disaring? Mengapa al-Qur'ân dan Sunnah yang mengandung ide-ide tertentu, menunda kelahirannya tanpa batas waktu? Mengapa evolusi dalam pemikiran agama tidak bisa dielakan? Mengapa kebenaran diserahkan

\footnotetext{
7 Nacim Pak-Shiraz, "Filmic Discourses on the Role of the Clergy in Iran", British Journal of Middle Eastern Studies, Vol. 34, No. 3 (2007), 344.

${ }^{8}$ Wright, "Iran's Greatest", 68.
} 
kepada generasi masa depan untuk menjelaskannya? Mengapa fatwa fuqaha Arab dan non-Arab bertentangan dengan watak masingmasing budayanya? Dan lagi, mengapa filsuf Islam berbeda dengan kaum sufi? Akhirnya dan yang terpenting, mengapa kita membutuhkan kebangkitan dan reformasi agama sekarang.??

Oleh karena itu Soroush mengingatkan kaum Muslim tentang posisinya di hadapan ajaran Tuhan. Soroush mengingatkan bahwa kaum Muslim siapapun dia-khususnya para ilmuwan dan pembaru agama-bukanlah orang yang berhak menentukan maksud Tuhan di dalam ajarannya. Mereka adalah para pejuang yang hanya berupaya memahami apa yang dikehendaki Tuhan di dalam al-Qur'ân sehingga ketika mereka sampai pada suatu pemahaman tertentu, maka tidak kemudian ia memaksakan pemahaman tersebut pada orang lain ataupun harus dianut olehnya. Dalam hal ini Soroush mengungkapkan bahwa kita umat manusia dikeluarkan dari surga dan membutuhkan wahyu. Kita ini profan dan tanpa daya. Hidup kita dikaburkan oleh setan dan pemahaman kita cenderung keliru. Kita tidak layak berbicara dan bertindak layaknya para Nabi. Adapun mengenai akal kita yang terbatas, kita mengetahui sedikit aroma kebenaran dan bertindak menurutnya. Kita adalah sârị̣ (penafsir agama) bukan shâri (perancang agama). Kita adalah orang yang terbujuk, bukan yang terjaga. Peringatkanlah orang-orang yang menganggap kata-katanya melampaui pemahaman biasa tentang agama: rasa bangga diri mereka mungkin pada akhirnya menggoda mereka untuk mengenakan Jubah Kenabian. Dalam hal ini Soroush menyatakan:

"We human beings are now expelled from heaven and deprived of revelation. We are profane and listless. Our life is blighted by Satan, and our understanding is fallible. To speak and act like prophets does not suit us. Apropos of our limited reason, we acquire a faint scent of the truth and act accordingly. We are sharihan (interpreters of religion), not sabri an (initiators of religion). We are the enticed, not the infallibles. Let them who deem their words above the mere understanding of the religion beware: their hubris may at long last tempt them to don the mantle of the prophets". ${ }^{10}$

Menurut Joshua Andressen, pemikiran Soroush tentang pemisahan agama dan pengetahuan agama dipengaruhi oleh filsafat sains yang memisahkan antara ilmu pengetahuan dan alam. Sebagai implikasi dari pandangan tersebut adalah bahwa agama itu sendiri

\footnotetext{
${ }^{9}$ Soroush, Reason, 33.

${ }^{10}$ Ibid., 37.
} 
ilahiah dan tidak bisa berubah. Sebaliknya, pengetahuan agama dan keagamaan pasti dan harus diharapkan berubah seperti pengakuan tentang pluralisme. Soroush mengusulkan agar pengetahuan agama dan keagamaan hendaknya disesuaikan dengan dasar prinsip-prinsip demokrasi sejauh hal itu terbuka, kritis, umum, dan plural. ${ }^{11}$ Hal itu karena bagi Soroush, konsep kebebasan, demokrasi, dan toleransi mengalir dari pemahamannya tentang Islam. ${ }^{12}$ Dalam konteks ini dapat dikatakan juga Soroush memiliki ketertarikan untuk menegaskan hubungan Islam dan demokrasi. Kesalahpahaman yang sering terjadi adalah demokrasi selalu diidentikkan sebagai liberalisme di satu sisi. Di sisi lain sharî́ah selalu diidentikkan keseluruhannya sebagai Islam, di mana keduanya sering dipertentangkan. ${ }^{13}$

Dengan demikian, para penafsir agama atau orang yang menghasilkan pengetahuan agama tidak dapat mengklaim bahwa pemahaman mereka adalah paling benar. Soroush menekankan bahwa para penafsir agama tidak bisa mengklaim bahwa pengetahuan agama mereka adalah esensi agama dan ilmu agama. Ilmu agama bukan pengetahuan personal dari seseorang manusia, melainkan merupakan cabang dari pengetahuan manusia yang mempunyai identitas kolektif dan dinamis dan tetap hidup terus melalui hubungan, kerja sama, dan kompetisi yang konstan di antara para ulama. Dengan demikian, ilmu agama penuh dengan kekeliruan, dugaan, dan keyakinan. ${ }^{14}$ Dengan demikian, pengetahuan agama itu secara mendasar adalah plural, baik dalam hal kepemilikian maupun perwujudannya, demikian juga bahwa ia bisa saja salah dan tidak absolut. ${ }^{15}$

Pemikiran-pemikiran Soroush tersebut telah menjadi satu proyek tersendiri untuk melapangkan jalan pluralisme dan anti-klaim kebenaran sepihak, perseorangan, parsial, dan golongan tertentu. Tentu saja yang menjadi target proyek ini adalah penghapusan klaim kepemilikan otoritas kebenaran agama. Dengan demikian menjadi logis manakala paradigma teologis yang memberikan peluang besar bagi tumbuhnya teologi dialogis di antara pemilik penafsiran agama

\footnotetext{
${ }^{11}$ Joshua Andresen, "Deconstruction, Secularism, and Islam", Philosophy Today, Vol. 56, No. 4 (2012) 383.

12 Irene Oh, "On Democracy, Violence, and the Promise of Islam", Journal of Church and State, Vol. 53, No. 1 (2011), 56.

13 Shah M. Nister Jahan Kabir, "Islam, Democracy, and The Question of

Coexistence”, Islam and Civilisational Renewal, Vol. 2, No. 3 (2011), 504.

14 Soroush, Reason, 34.

15 Andresen, "Deconstruction", 384.
} 
tersebut bertemu dengan pemikiran politik demokrasi Soroush. Hamid Mavani menyebutkan bahwa argumen yang cukup favorit di Iran selama tahun-tahun pertama Revolusi Iran adalah kedaulatan rakyat dan pembatasan kekuasaan para hakim, telah dibingkai dalam media baru dengan menafsirkan kembali wewenang keagamaan. Soroush dan para pemikir Iran lainnya yakni bahwa klaim Khomeini di mana sumber ajaran telah berisi bukti yang cukup untuk membuat kasus bahwa kualifikasi para hakim memiliki wilayah kekuasaan yang sama sebagaimana Nabi dan Imam yang maksum adalah tidak dapat dibenarkan, memihak, merupakan sebuah tujuan radikal dari perspektif tradisional Shî'ah. ${ }^{16}$

Katajun Amirpur menilai Soroush dipengaruhi oleh pemikiran teologi liberal dalam Dunia Kristen khususnya pemikiran John Hick. Soroush sangat terkesan dengan pandangan dan sikap pluralistik John Hick ketika berinteraksi dengan orang-orang non-Kristen. Hick mulai dengan bergerak menuju pandangan pluralistiknya dalam agama. Hick mencatat bahwa masyarakat non-Kristen yang ia temui memiliki nilainilai dan sikap moral yang sama dengan masyarakat Kristen. Dengan fenomena ini, Hick mengungkapkan pertanyaan yang sangat mendasar yakni bagaimana mungkin kecintaan kepada Tuhan dapat menghukum masyarakat non-Kristen yang mendukung nilai-nilai pemujaan atas Kristianitas dimasukkan ke dalam neraka secara abadi. ${ }^{17}$

Charles Kurzman memposisikan Soroush sebagai pembaru yang menolak absolutisme pemahaman keagamaan karena pemahaman keagamaan — sebagaimana pemahaman keagamaan yang lainmemiliki potensi kesalahan dan dapat dikritik. Dampak tesis Soroush tersebut adalah bahwa keilmuwan di Hawzeh cenderung bisa dikritik dan dapat diragukan. Secara personal, produk pemikirannya tersebut mengakibatkan ia harus dipecat dari kampus dan pernah memperoleh perlakuan yang tidak menyenangkan dari personel tentara. ${ }^{18}$ Pemikiran Soroush telah memposisikan Soroush secara berlawanan dengan

\footnotetext{
${ }^{16}$ Hamid Mavani, "Khomeini's Concept of Governance of the Jurisconsult (Wilayat al-Faqih) Revisited: The Aftermath of Iran's 2009 Presidential Election", The Middle East Journal, Vol. 67 No. 2 (2013), 227.

${ }^{17}$ Katajun Amirpur dan Sasan Tavassoli, "Christian Encounters with Iran: Engaging Muslim Thinkers after the Revolution (Review)", International Journal of Middle East Studies, Vol. 44, No. 3 (2012), 588.

${ }^{18}$ Charles Kurzman, "Critics within: Islamic Scholars' Protests against the Islamic State in Iran", International Journal of Politics, Culture, and Society, Vol. 15, No. 2 (2001), 346.
} 
ulama yang mengaku sebagai pengganti Imam dan penjaga kebenaran, fuqahâ, dan pendukung wilâyat-i faqî̉. ${ }^{19}$ Ditambah lagi secara terangterangan Soroush dalam Reuters menyatakan bahwa konsep wilâyat-i faqîh yang telah diperkenalkan pasca-Revolusi Iran 1979 tidak tepat. Alasan Soroush dalam hal ini adalah bahwa meskipun agama itu sendiri sakral, penafsiran atas agama itu tidak sakral, bisa dimodifikasi, bisa didefinisikan kembali. ${ }^{20}$

\section{Otoritarianisme Pemahaman Keagamaan}

Sebuah pemahaman dan penafsiran keagamaan merupakan ijtihad yang bisa memiliki nilai kebenaran dan mengandung kelemahan atau kesalahan. Dalam konteks ini Soroush menegaskan bahwa sebuah bentuk pemahaman dan penafsiran keagamaan tidak dapat dijadikan sebagai satu-satunya pemahaman dan tafsiran yang paling benar di antara pemahaman dan tafsiran keagamaan lainnya. Adanya pengakuan akan pemahaman keagamaan yang otoritatif dapat mengarahkan pada sikap keagamaan yang otoriter hingga berujung pada tirani keagamaan. Sikap otoriter yang dilandasi semangat merasa memiliki kebenaran paling tinggi telah menggoda para ulama untuk menyalahkan pemahaman keagamaan lain dan bersikap otoriter hingga pada pelanggaran hak-hak asasi manusia.

Fenomena yang sering terjadi adalah bahwa ketika seseorang pengkaji agama sampai pada atau menghasilkan sebuah pemahaman dan pemikiran keagamaan, ia menjadi lupa hingga ia bersikap layaknya Nabi yang berhak menentukan arah dan maksud Tuhan. Para pembaru agama atau ilmuwan agama bukanlah orang yang berhak atas itu sehingga tidak sedikitpun mereka diperkenankan mengambil jubah kenabian. Mereka harus bersikap terbuka dan bebas atas segenap pemahaman keagamaan yang lain. Menurut Soroush menerima kedaulatan agama tidak berarti mengatasnamakan kata-katanya sebagai sabda Nabi dan merebut kedudukannya. Penerimaan ini justru bermakna upaya tulus untuk memahami pesannya melalui kajian yang berulang-ulang terhadap al-Qur'ân dan Sunnah. Para ulama tidak memiliki status atau pengabdian lain kecuali ini. Mereka adalah para penyusun ilmu agama yang tidak sempurna. Perjuangan mereka yang berharga untuk memahami al-Qur'ân dan Sunnah tidak menghasilkan pengetahuan suci. Nabi Islam adalah nabi terakhir dan agamanya

\footnotetext{
${ }^{19}$ Jahanbakhsh, Islam, 150.

${ }^{20}$ Ladan Boroumand dan Roya Boroumand, "Illusion and Reality of Civil Society in Iran: An Ideological Debate”, Social Research, Vol. 67, No. 2 (2000), 321.
} 
adalah agama terakhir. Akan tetapi tidak ada pakar hukum (faqîh) atau pakar tafsir (mufassir) yang menjadi pakar hukum atau pakar tafsir terakhir. $^{21}$

Pemikiran ini senada dengan pemahaman M. Fethullah Gulen ketika menjelaskan tentang kebenaran Nabi dan pemikiran manusia biasa. Menurut Gulen, Tuhan mengutus para Nabi kepada manusia untuk mengajarkan makna penciptaan dan kebenaran tentang sesuatu dan menyingkap misteri sejarah dan kejadian alam. ${ }^{22}$ Karena memang sudah menjadi tugas Nabi untuk menunjuki manusia kepada kebenaran. ${ }^{23}$ Kesempurnaan Nabi itu digambarkan Gulen sebagai utusan Tuhan yang paling murah hati, paling ringan tangan, paling terkemuka, paling sabar, dan paling tekun. Dia adalah orang yang paling benar dalam ucapannya, paling baik hati dan menyenangkan dalam persahabatan, dan paling mulia dalam keluarga. Siapa yang melihatnya, pasti dilanda rasa kagum. ${ }^{24}$

Otoritaritarianisme keagamaan lahir karena adanya pemahaman bahwa para ulama mengklaim bahwa mereka telah diberi amanah agama oleh Nabi atau Rasul sehingga para ulama ini harus melaksanakan amanah ini. Jika tidak melaksanakan amanah tersebut, maka mereka di Hari Kiamat akan memperoleh hukuman yang berat dari para Nabi. Dalam hal ini Soroush menjelaskan:

"Their conception of the Prophet, too, is much the same: Someone who had been disqualified in an election took his grievance to one of the clerical members of the Guardian Council and said: 'If you don't uphold my right, after Judgment Day I'll complain about you to the Seal of the Prophets.' The cleric smiled and said: 'Let me set you straight; the Seal of the Prophets believes in neither freedom nor elections". ${ }^{25}$

Permasalahan bukan terletak pada penerimaan amanah keagamaan karena semua umat memang harus merasa memiliki amanah kenabian untuk mengajak orang kepada kebajikan. Permasalahannya adalah perasaan menerima kebenaran sehingga menjadikan sang ulama merasa memiliki kebenaran paling otoritatif yang diyakini diberikan

\footnotetext{
${ }^{21}$ Soroush, Reason, 37.

${ }^{22}$ M. Fethullah Gulen, The Essentials of the Islamic Faith (t.t.: Feedsbooks, 2005), 140.

23 Ibid., 148.

${ }^{24}$ Ibid., 149.

25 Abdolkarim Soroush, "The Crust and the Core of Rule by the People" dalam http://drsoroush. com/en/the-crust-and-the-core-of-rule-by-the-people/diakses 17 Desember 2015.
} 
oleh Nabi dan sekaligus menganggap paling benar dan menolak pemahaman dan pemikiran yang lain.

Selain itu, penolakan atas kemajemukan pemikiran merupakan penyebab dari lahirnya tirani pemikiran. Dalam konteks ini, Soroush banyak melayangkan kritiknya kepada kalangan ulama yang dinilainya menolak kemajemukan pemikiran. Para ulama menurut Soroush menolak kebebasan dan pemilihan umum yang dinilai oleh ulama sebagai produk liberalisme, keserbabolehan, dan tidak bermoral. Pemikiran keagamaan ulama lebih mengedepankan kewajiban daripada hak. Kitab figh yang ada berisi setengah bagian, bahkan setengah halaman tentang hak-hak manusia. Sekolah pascasarjana agama di Qom dan Najaf tidak tertarik pada filsafat dan hukum modern. Mereka mencari ide dan utopia mereka dalam masa pramodern, masyarakat berorientasi kewajiban, yang menumbuhsuburkan dasar tirani.

Salah satu perhatian penting Soroush kaitannya dengan tafsir agama sebagai penyebab otoritarianisme keagamaan ini adalah "perselingkuhan" antara pemilik tafsir keagamaan dengan kekuasaan politik. Hal ini wajar mengingat para ulama pemilik tafsiran keagamaan di Iran khususnya pasca-Revolusi Iran 1979 adalah para ulama yang tergabung dalam kelompok fuqahâ, dan pendukung wilâyat$i$ faqî̉. Hubungan antara keulamaan dan politik dinilai Soroush sebagai cikal otoritarianisme keagamaan. Oleh karena itu untuk membendung otoritarianisme yang berujung pada tirani keagamaan ini, Soroush memulai dari penyebaran paradigma demokrasi dan pemikiran anti-ideologisasi agama. ${ }^{26}$ Soroush hendak memangkas paham legalitas ulama sebagai pemimpin agama dan pemimpin politik yang hendak menjadikan tafsir keagamaan mereka sebagai pemahaman keagamaan satu-satunya yang resmi dan dianggap paling benar.

Bagi Soroush, hierarki keagamaan adalah penyebab utama munculnya gerakan anti-agama dan anti-gereja. Pemberontakan ini tidak melawan Tuhan, tetapi melawan mereka yang memerintah dan melakukan kezaliman atas nama Tuhan. Mereka yang menjadi sasaran ketidakadilan, intimidasi, penipuan dan kejahatan seperti itu, meskipun mereka adalah orang-orang yang taat beragama, bangkit

\footnotetext{
${ }^{26}$ Penilaian yang senada dengan ini disampaikan oleh Bruce B. Lawrence, "Muslim Ethics: Emerging Vistas (Review)", International Journal of Middle East Studies, Vol. 38, No. 1 (2006), 164.
} 
melawan rezim itu, setidak-tidaknya secara diam-diam mendukung pemerintah alternatif yang sekuler. Pada masa prasekuler, agama menjadi sponsor rezim politik. Agama memberi legitimasi dan legalitas pada politik. Akan tetapi, kezaliman, ketidakadilan, dan pendewaan yang timbul dari aliansi ini terbukti tidak bisa ditoleransi. Kaum yang arif di kalangan rakyat mulai bertanya kepada diri sendiri; mengapa manusia, padahal mereka masih manusia, dapat menjalankan pemerintahan ilahiah (yang sempurna)?. ${ }^{27}$

Konsistensi Soroush mengharuskannya menegaskan bahwa pemerintahan manusia adalah pemerintahan manusia dan tidak ada unsur yang dapat dinisbahkan kepada Tuhan. Apa yang terjadi di kalangan manusia, baik atas nama Tuhan maupun yang lain, sudah barang tentu manusiawi dan tidak sempurna. Oleh karena itu, pemerintahan manusia harus terbuka terhadap supervisi dan pengkajian secara rasional. Bidang sosial dan politik tidak memberi ruang untuk pertunjukan irasional dan supernasional yang menuntut saksi pasif dan kepasrahan. Segala sesuatu yang memasuki alam, termasuk agama dan wahyu, akan mengikuti jalan alam. Segala sesuatu yang memasuki masyarakat manusia akan menjadi manusiawi. Hal ini berarti tidak ada fenomena yang sangat superalamiah dan metasosial. Bahkan, makhluk spiritual pun akan mengenakan pakaian badaniah begitu memasuki wilayah alam manusia. Kita menganggap alam manusia dan urusan manusia sebagai masalah alami yang telah menjadi alat untuk meralat kesalahan masa lampau yang merugikan. ${ }^{28}$

Menurut Nacim Pak-Shiraz, Soroush mempertanyakan penegakan keagamaan dan kekuasaan para ulama yang diberikan atas mereka. Soroush yang pada walnya merupakan sekutu dekat kalangan Republik Islam Iran telah menjadi pengkritik yang terang-terangan. Soroush mengritik monopoli atas Islam yang dilakukan oleh para ulama. ${ }^{29}$ Dampak negatif kekuasaan agama yang didasarkan pada satu penafsiran agama tertentu ini yang melahirkan pemerintahan represif. Soroush muncul ketika pemerintahan menjadi otoriter-represif bertepatan dengan merebaknya tuntutan demokrasi sehingga diperlukan sebuah tinjauan atas bentuk baru wacana teologi dan analisa politik. ${ }^{30}$

27 Soroush, Reason, 60-61.

28 Ibid., 61.

29 Pak-Shiraz, "Filmic Discourses, 336.

30 Ahmad Ashraf dan Ali Banuazizi, Iran' Tortuous Path toward "Islamic Liberalism"“, Journal of Politics, Culture, and Society, Vol. 15, No. 2 (2001), 250. 
Soroush menolak pemahaman bahwa Islam sebagai ideologi politik. Ideologi keagamaan tidak boleh mengatur negara modern karena hal itu akan cenderung pada totalitarianisme. Penggunaan ideologi keagamaan dalam pemerintahan akan menghalangi pertumbuhan pengetahuan agama. Masyarakat akan menjadi religius dengan sendirinya dan bukan oleh ketentuan yang diatur oleh pemerintah. ${ }^{31}$ Seterusnya, Soroush menurut Wright menolak teokrasi sebagai bentuk pemerintahan yang tepat. Pemerintahan yang ideal menurutnya bukan yang dipimpin oleh para Mullah, akan tetapi pemimpin yang sekuler. ${ }^{32}$ Menurut Kevan Harris, pemikiran Soroush mengarah pada liberalisme politik karena Soroush berpendapat bahwa Iran membutuhkan pergerakan tanpa ideologi. Gerakan ini mengizinkan keyakinan plural dan ruang publik bagi dialog tanpa rasa takut akan hukuman. ${ }^{33}$ Bagi Soroush, ideologi dipandang sebagai korupsi intelektual, keinginan nafsu, dan kebencian akal. ${ }^{34}$

Mehrzad Boroujerdi menilai Soroush sebagai reformis yang menantang legitimasi tafsiran tradisional dari keagamaan konservatif yang memiliki kekuatan politik tak terkendali. Soroush dan kalangan reformis lainnya mengutuk mutasi Islam sebagai agama ke dalam ideologi politik. Revolusi dapat menjadi baju pengekang Islam dan menjadi bahaya bagi Islam karena dapat mendatangkan citra buruk bagi Islam. ${ }^{35}$ Sebagaimana diungkap Forough Jahanbakhsh, Soroush berbeda dengan rekannya secara modernis yang memiliki keinginan membangun sebuah ideologi Islam. Soroush membalikkan keinginan ini dengan memulai sebuah upaya deideologisasi Islam. ${ }^{36}$ Situasi inilah yang membuat Soroush dipandang lebih berbahaya bagi rezim dibandingkan dengan kritik kaum sekularis dalam konteks penegasian ideologisasi Islam dalam proses pembentukan negara Islam Iran. ${ }^{37}$

Pemikiran Soroush terkait dengan perlunya umat Islam meninggalkan absolutisme dan tirani pemikiran ini dipengaruhi oleh

\footnotetext{
31 Wright, "Iran's Greatest”, 69.

${ }^{32}$ Ibid., 70.

${ }^{33}$ Kevan Harris, "Democracy in Iran (Review)", Middle East Journal, Vol. 64, No. 4 (2010), 661.

34 John Von Heyking, "Mysticism in Contemporary Islamic Political Thought: Orhan Pamuk and Abdolkarim Soroush", Humanitas, Vol. 19, No. 1 (2006), 81.

35 Mehrzad Boroujerdi, "Comparative Politic (review)", Perspectives on Politics, Vol. 9, No. 3 (2011), 730.

${ }^{36}$ Jahanbakhsh, Islam, 151.

${ }^{37}$ H. E. Chehabi, "Eighteen Years Later: Assessing the Islamic Republic of Iran", Harvard International Review, Vol. 19, No. 2 (1997), 31.
} 
afiliasi Soroush pada perjuangan Hak-hak Asasi Manusia. Soroush begitu dikenal dalam perjuangan HAM dan Demokrasi di Iran pascaRevolusi Iran 1979. Menurut David Hollenbach, Soroushsebagaimana Abû al-A'lâ al-Mawdûdî dan Sayyid Quṭb-banyak menyoroti ketidakdilan sosial yang mengakibatkan kemiskinan serta menyerukan perlunya keadilan ekonomi dan sosial. ${ }^{38}$ Demikian juga dengan pemikirannya terkait dengan pluralisme. ${ }^{39}$

Menurut Daniel Brumberg, ide Soroush tentang "menyelamatkan Islam dengan memisahkan ulama dan negara" dipengaruhi oleh teori Weber mengenai pembedaan antara pengetahuan agama dengan ilmu pengetahuan dan oleh karenanya tidak menyediakan dasar bagi politik modern. Dengan mendefinisikan kembali aspek-aspek mistik Ayatullah Khomeini dan ideologi Ali Syari'ati dalam cara yang jelas ke arah individu daripada pengalaman karismatik masyarakat, Soroush mencoba menyebarkan visi reformasi politik yang menginspirasi secara spiritual dan secara politik rasional. ${ }^{40}$ Soroush mendukung penafsiran rasional atas Kitab Suci yang mengarah pada pemisahan agama dan negara. ${ }^{41}$ Pemikiran Soroush dalam konteks peran sosial dan politik Islam tersebut mendatangkan makian, fitnah, dan kekerasan fisik dari aktivis Hizbullah. ${ }^{42}$ Dalam wilayah inilah Soroush mulai berseberangan dengan Khomeini dan Syari'ati, karena dua figur ini menginginkan kekuasaan ulama (wilâyat-i faqî̉) dalam pemerintahan, sementara Soroush menginginkan pemisahan kepemimpinan agama para ulama dengan kekuasaan negara. ${ }^{43}$

De-ideologisasi agama dinilai sangat penting bagi pencegahan berkembangnya pengetahuan atau tafsiran agama yang absolut dan otoriter. Deideologisasi agama juga penting bagi proses integrasi sosial antara umat Islam dan masyarakat Barat. Sebagaimana diungkap

38 David Hollenbach, "Comparative Ethics, Islam, and Human Rights: Internal Pluralism and the Possible Development of Tradition", Journal of Religious Ethics, Vol. 38, No. 3 (2010), 582-583.

39 Kathleen Foody, "Behrooz Ghamari-Tabrizi, Islam and Dissent in Postrevolutionary Iran: Abdolkarim Soroush, Religious Politics and Democratic Reform", Contemporary Islam, Vol. 6, No. 2 (2012), 224.

40 Daniel Brumberg, "Dissonant Politics in Iran and Indonesia", Political Science Quarterly, Vol. 116, No. 3 (2001), 391.

${ }^{41}$ Mustafa Malik, "No god but God: The Origins, Evolution, and Future of Islam", Middle East Policy, Vol. 12, No. 2 (2005), 147.

42 George Joffé, “At the Turning Point”, The World Today, Vol. 55, No. 4 (1999), 12.

43 Mahmood Monshipouri, "Religion and Politics in Modern Iran: A Reader (Review)", Middle East Studies Association Bulletin, Vol. 40, No. 2 (2006), 273. 
Nahla Shahrouri, umat Islam memeluk Islam sebagai identitas budaya daripada sebagai sumber kebenaran dan keselamatan. Hal ini yang oleh Soroush dinilai sebagai penyebab terjadinya benturan antara Muslim dan masyarakat Barat. Oleh karenanya menurut Soroush, Muslim harus dapat memisahkan kebenaran agama dan ideologi agar mereka dapat merangkul demokrasi. ${ }^{44}$ Di sisi lain ada beberapa Muslim yang bertendensi menjadikan Islam sebagai kekuatan global daripada sebagai kebenaran yang diwahyukan Tuhan. ${ }^{45}$

Nadia Bernaz menilai bahwa Soroush sering melontarkan pertanyaan mendasar yang bahkan dapat membingungkan para filsuf politik yakni "Siapakah yang menjaga para penjaga"? atau dengan kata lain jika pemimpin agama juga menjadi pemimpin politik-untuk menggabungkan agama ke dalam ideologi politik sebagai dasar bagi monopoli wilayah publik — siapa kemudian yang akan mengawasi dan memaksakan kekuasaan mereka guna memelihara wilayah publik yang beragam. Soroush membuat argumen yang lebih jauh bahwa perkawinan agama dan politik bertentangan dengan pluralisme dan toleransi yang dibutuhkan oleh demokrasi. Bernaz menyimpulkan bahwa bagi Soroush demokrasi dan hak-hak asasi manusia tidak dibenarkan oleh agama, tetapi membutuhkan tambahan pembenaran dari agama. Hal ini pasti merupakan panggilan untuk sekulerisme dalam beberapa pengertian, tetapi panggilan ini didasarkan pada mistisisme keagamaan dan hubungan yang terus-menerus pada tradisi Islam. ${ }^{46}$ Meskipun demikian, Bernaz agak keliru dalam menilai Soroush karena bukan nilai-nilai Hak Asasi Manusia dan demokrasi itu tidak dibenarkan oleh agama, tetapi tafsiran agama tentang dua isu tersebut yang belum dikembangkan oleh para penafsir agama.

\section{Teori Penyusutan dan Pengembangan Interpretasi Agama}

Teori penyusutan dan pengembangan interpretasi agama (the contraction and expansion of religious interpretation) merupakan paradigma yang ditawarkan Soroush untuk membendung arus otoritarianisme

\footnotetext{
${ }^{44}$ Soroush, Reason, 24. Lihat juga Nahla Shahrouri, "Does a Link Exist Between Democracy and Terrorism?", International Journal on World Peace, Vol. 27, No. 4 (2010), 54.

45 Anders Strindberg dan Mats Wärn, "Realities of Resistance: Hizballah, The Palestinian Rejectionists, and al-Qaiida Compared", Journal of Palestine Studies, Vol. 34, No. 3 (2005), 30.

${ }^{46}$ Nadia Bernaz, "Life Imprisonment and the Prohibition of Inhuman Punishments in International Human Rights Law: Moving the Agenda Forward", Human Rights Quarterly, Vol. 35, No. 2 (2013), 503.
} 
sebuah penafsiran agama. Teori ini dipandang dapat menjadi pilar penguat pluralisme dan nilai-nilai demokrasi. Soroush mengingatkan agamawan untuk tidak terjebak dalam sebuah penafsiran agama tertentu, apalagi menobatkannya sebagai satu-satunya pemahaman keagamaan yang benar. Satu hal yang menjadi sasaran peringatan keras Soroush adalah dijadikannya sebuah pemahaman agama sebagai sebuah ideologi bagi negara, sehingga otoritarianisme yang lahir dari fenomena tersebut adalah otoritarianisme agama dan dapat mengancam nilai-nilai demokrasi.

Menurut Soroush, yang terpenting dalam upaya memahami pemikiran keagamaan manusia adalah keharusan untuk membedakan mana agama sebagai sebuah ajaran Tuhan dan pemikiran keagamaan manusia sebagai produk manusia dan sebagai refleksi atas ajaran agama. Dari pembedaan ini nantinya akan diketahui unsur mana yang sebenarnya sakral, mutlak kebenarannya dan unsur mana yang profan, tidak asli dan tidak mutlak kebenarannya. Dalam hal ini Soroush menegaskan bahwa yang sebenarnya terjadi adalah selama orang belum dapat membedakan antara agama dan pemahaman agama, maka ia tidak akan menemukan jawaban yang tepat untuk pertanyaanpertanyaan yang mengusik tersebut. Benar bahwa kitab suci agama (menurut penilaian para pengikutnya) tidak bercacat, namun sama benarnya juga mengatakan bahwa pemahaman manusia akan agama itu bercacat. Agama itu suci dan ukhrawi, tetapi pemahaman tentang agama adalah manusiawi dan duniawi. Yang konstan adalah agama (din) sedangkan yang mengalami perubahan adalah ilmu agama (alma'rifah al-dinîyah). ${ }^{47}$

Dalam konteks ini, Soroush sedikit berbeda dengan rekan sesama modernis dalam upaya membangkitkan atau memodernisasikan Islam. Menurut Vakili, pada umumnya para pemikir Muslim kontemporer sering berpendapat bahwa Islam harus "direkonstruksi" atau agar sesuai dengan kebutuhan masyarakat dan umat Muslim modern. Tetapi Soroush berpendapat lain. Ia memang menerima perlunya merekonsiliasi perubahan-perubahan dalam dunia modern dengan kebakaan agama, tetapi dia tidak setuju dengan rekonstruksi atau pembangkitan kembali Islam. Bagi Soroush, Islam tidak berubah-ubah dan segala upaya untuk merekonstruksi Islam adalah sia-sia sekaligus

${ }^{47}$ Soroush, Reason, 31. 
sesat. Agama tidak perlu diubah. Pemahaman orang tentang agamalah yang perlu diubah. ${ }^{48}$

Oleh karena hanya merupakan refleksi dan upaya memahami sebuah ajaran agama, maka segala bentuk produk pemikiran dan buah pemahaman terhadap agama tentu saja memiliki kelemahankelemahan alias tidak mutlak kebenarannya. Oleh karenanya segenap pemikiran keagamaan tidak bebas dari kelemahan, kesalahan dan kecacatan. Menurut Soroush, agama tidak bimbang dalam berbicara tentang tujuannya dan menjelaskan tentang kebaikan dan keburukan tetapi kecacatan itu dijumpai dalam pemahaman manusia tentang maksud agama. Agama tidak membutuhkan perbaikan dan penyempurnaan. Akan tetapi, ilmu agama, yang bersifat manusiawi dan tidak sempurna secara terus-menerus perlu diperbaiki. Agama bersih dari segala kultur dan buah pikiran manusia, tetapi ilmu agama-tanpa ragu sedikitpun-terpengaruh oleh hal-hal demikian. Kaum revivalis bukan pembuat hukum (shâri') melainkan penafsir (sârib). Walaupun agama tidak memiliki kecacatan atau kekurangan, kecacatan banyak ditemukan dalam tafsir. Nabi tidak bungkam maupun mengabaikan amanatnya sebagai pembawa wahyu ilahiah; pikiran manusialah yang terpengaruh oleh kebutuhan dan pengabaian. Akal tidak bisa membantu menyempurnakan agama; akal berupaya keras memperbaiki pemahamannya sendiri terhadap agama. Sharî́ah agama tidak pernah setara dengan opini manusia sehingga mustahil ada kesesuaian atau ketidaksesuaian antara keduanya, pemahaman seorang manusialah yang bisa jadi sama atau tidak sama dengan pemahaman manusia yang lain. ${ }^{49}$

Soroush menegaskan bahwa manusia biasa tidak dapat mewarisi keistimewaan para Nabi dan Rasul sehingga hasil pemikiran dan pengalaman keagamaan seseorang tidak dapat dijadikan sebagai landasan hukum secara mutlak sebagaimana layaknya Nabi. Kenyataan bahwa pengalaman keagamaan seseorang terkait dengan yang lain, yang terdapat dalam dewan perwalian (wilayat-e tashri i) berakhir dengan wafatnya Nabi Islam dan tidak ada seorangpun yang memiliki kewajiban, hak, dan pengalaman seperti ini lagi. Oleh karenanya, siapapun yang datang setelah perbuatan Nabi dalam wilayah kenabiannya, kewajiban mereka mengalir dari kewajibannya dan otoritas mereka di balik ucapan mereka divalidasi oleh

\footnotetext{
48 Vakili, “Abdolkarim Soroush and Critical Discourse in Iran”, 153.

${ }^{49}$ Soroush, Reason, 31.
} 
otoritasnya. Setelah Nabi, tidak ada keyakinan keagamaan seseorang, kepastian, pengalaman, dan pemahaman yang setaraf dengan keyakinan, kepastian, pengalaman, dan pemahaman Nabi atau sama dampaknya. ${ }^{50}$

Melalui teori penyusutan dan pengembangan interpretasi agama, pemahaman terhadap agama sebagai bagian dari ilmu agama memiliki tujuan yang sama dengan semua disiplin keilmuwan dan pengetahuan manusia lainnya jika ilmu pengetahuan lain baik itu eksak maupun non-eksak tersebut dipergunakan sebagai pisau analisis untuk memahami agama. Soroush menjelaskan bahwa teori penyusutan dan pengembangan interpretasi agama membuka rahasia semua pertanyaan seperti itu. Teori ini membedakan antara agama dan ilmu agama. Teori ini menilai ilmu agama sebagai suatu cabang ilmu pengetahuan manusia dan menganggap pemahaman kita tentang agama berevolusi bersama cabang-cabang ilmu pengetahuan manusia lainnya. Pengetahuan dan kebutuhan zaman yang baru membuat faqîh pemberani dapat memainkan peran bidan untuk ibu-ibu sharî́ah yang hamil dan menghidupkan semangat kepekaan Yunani dalam tubuh pemahaman agama. Lalu, menjadi jelas bahwa pengetahuan agama bukan kitab suci yang mengambil pigmen dan aroma budaya, mengalami perubahan dan harus dibersihkan. Kaum revivalis yang merupakan para filsuf agama yang berempati, tidaklah mengganti agama dengan pemahaman mereka sendiri tentang agama. Mereka hanya mengganti suatu pemahaman agama dengan pemahaman yang lain. Kaum revivalis, meskipun menerima sifat kebakaan al-Qur'ân dan Sunnah, menyegarkan kembali dan melengkapi pengetahuan kita tentangnya. Bagian yang tetap adalah agama; bagian yang berubah adalah pemahaman agama. ${ }^{51}$

Menurut Haidar Bagir, teori perluasan dan penyempitan agama mengajukan tiga prinsip. Pertama, prinsip koherensi atau keterpaduan dan korespondensi; segenap pemahaman tentang agama (benar maupun tidak benar) dilakukan dalam konteks sekumpulan pengetahuan manusia dan-disadari atau tidak-selalu menyesuaikan diri dengan kumpulan pengetahuan manusia tersebut. Kedua, prinsip interpenetrasi; penyempitan atau perluasan di dalam sistem pengetahuan manusia dapat merembesi wilayah pemahaman kita

50 Abdulkarim Soroush, The Expansion of Prophetic Experience: Essays on Historicity, Contingency and Plurality in Religion (Leiden: Brill, 2009), 46.

${ }^{51}$ Soroush, Reason, 33. 
tentang agama. Ketiga, prinsip evolusi; sistem pengetahuan manusiayakni ilmu pengetahuan dan filsafat manusia-mengalami perluasan dan penyempitan. ${ }^{52}$

Menurut Hashas, teori Soroush tersebut berdampak pada seluruh hasil rancangan Soroush yakni dunia yang secara a priori bersifat plural di mana dia menyebutnya "pluralisme negatif" dan secara a posteriori juga bersifat plural, dan dia menyebutnya "pluralisme positif". Dengan konsep ini Soroush sampai pada satu kesimpulan bahwa manusia dan kaum beriman tidak bisa berharap terlalu banyak pada agama-di mana Soroush menyebutnya sebagai "agama minimalis" melawan orang "maksimalis", untuk sejarah dan orang beriman itu sendiri yang menambahkan pada agama hal-hal "kebetulan" yang berkedok "esensialis". Untuk menyingkap "esensial" agama maka dibutuhkan penyingkapan awal pewahyuan dan hal ini kemudian terbangun dalam cahaya pengalaman Kenabian, urgensi kesejarahan, dan interaksi kemanusiaan. Hasil dari studi agama adalah pengetahuan tentang agama tersebut dan bukan agama itu sendiri. ${ }^{53}$

Jika Allah menjamin bahwa al-Qur'ân akan senantiasa terjaga dari kepunahan dan kerusakan sehingga selamanya ia akan tetap menjadi petunjuk bagi manusia, maka tidak demikian halnya dengan segala bentuk penafsiran, pemahaman dan pemikiran manusia terhadap alQur'ân. Penafsiran, pemahaman, dan pemikiran al-Qur'ân sepenuhnya manusiawi dan tidak terjamin kebenaran maupun keamanannya. Ia bisa saja bersifat sementara di mana tidak dapat berlaku dalam waktu dan tempat yang berubah-ubah. Bagi Soroush, praktik agama tidak bisa ditemporalkan atas tuntutan siapapun; ia menjadi temporal dengan sendirinya. Temporalisasi bukanlah sifat agama, melainkan sifat ilmu agama. Orang harus memahami apa hakikat agama agar mampu memperoleh bentuk temporal ke dalam bentuk agama. Pemahaman ini diperoleh melalui pengkajian terhadap ilmu agama yang pada gilirannya selalu terikat waktu. Oleh karena itu, memaksakan tatanan temporal ke dalam bentuk agama itu sendiri hanya mungkin melalui ilmu agama yang temporal. Betapapun, pokok pemahaman teori penyusutan dan pengembangan interpretasi agama

52 Haidar Bagir, "Kata Pengantar: Soroush: Potret Seorang Muslim "Liberal" dalam Abdul Karim Soroush, Menggugat Otoritas dan Tradisi Agama, Mahmoud Sadri dan Ahmad Sadri (eds.), terj. Abdullah Ali (Bandung: Mizan, 2002), xxiii.

53 Mohammed Hashas, "Abdolkarim Soroush: The Neo-Mu'tazilite that Buries Classical Islamic Political Theology in Defence of Religious Democracy and Pluralism", Studia Islamica, Vol. 109, No. 1 (2014), 152-152. 
terjadi dengan memahami dua perbedaan utama: pertama, perbedaan antara ilmu agama dan pemahaman kita tentang ilmu agama dan, kedua, perbedaan antara pengetahuan pribadi tentang agama dan ilmu agama. Jika seseorang tidak menimbang dua benteng yang besar ini, dia tidak akan dapat menikmati padang rumput dan cakrawala teologi yang luas dan terbuka. ${ }^{54}$

Melalui teori penyusutan dan pengembangan agama, Soroush ingin menjelaskan secara rinci tentang proses kerja dan terbentuknya sebuah pemahaman terhadap agama serta bagaimana kemudian segenap pemahaman keagamaan itu berubah oleh karena latar belakang sejarah yang mengitarinya. Sebaliknya, Soroush menegaskan bahwa melalui teorinya dia tidak bermaksud memperbarui agama, merelatifkan atau bahkan mendekonstruksi. Kiranya Soroush banyak berkutat pada upayanya untuk menjelaskan secara epistemologis mengenai arti sebuah 'pemahaman keagamaan'. Tujuan teori penyusutan dan pengembangan interpretasi agama ini bukan untuk memecahkan perselisihan antara yurisprudensi yang tradisional dan yang dinamis (fighi sonnati va fighi pouya); tidak juga untuk memodernkan agama, menginterpretasi kembali atau menyempurnakan sharî́ah, merelatifkan atau mengingkari kebenaran. Akan tetapi teori ini bermaksud menjelaskan secara terperinci proses memahami agama dan cara pemahaman ini mengalami perubahan. Teori ini mengemukakan bahwa selama rahasia memahami agama dan transformasi pemahaman ini tidak diungkapkan, upaya membangkitkan kembali agama tetap tidak akan sempurna. Jadi, teori penyusutan dan pengembangan interpretasi agama, yang pada dasarnya adalah teori "interpretasi-epistemologi", merupakan bagian dari tiga bidang ilmu yang lain juga: kalâm (teologi Islam), usû́l al-fiqh (logika terapan dalam yurisprudensi agama), dan irfân (dimensi esoteris Islam). ${ }^{55}$

Soroush menguraikan bahwa komposisi teorinya terdiri dari tiga unsur penting dan merupakan disiplin keilmuwan yang utama dalam Islam yakni ilmu kalam atau teologi, ushul figh, dan tasawuf. Meski demikian, visi penting Soroush dalam pemikirannya adalah reformasi. Rancangan Soroush meluncurkan secara mendasar arah baru dalam teologi dan politik Islam (teologi politik) yang dibangun atas

\footnotetext{
54 Soroush, Reason, 33-34.

55 Ibid., 34.
} 
mistisisme klasik dan teologi rasional (Mu'tazilah). ${ }^{56}$ Abad 20 menunjukkan adanya penyerapan pemikiran teologi $\mathrm{Mu}^{6}$ tazilah di kalangan pemikir Islam rasionalis. Dalam satu penilaian, pengaruh Mu'tazilah telah memberi inspirasi signifikan dalam karya penting Soroush. ${ }^{57}$

Pertama, teori ini adalah bagian dari ilmu kalam sebab berhubungan dengan teologi, juga karena teori ini menjelaskan kadar sejauhmana asumsi dan ekspektasi dari agama kita sebelumnya mempengaruhi pemahaman kita tentang al-Qur'ân dan Sunnah. Kedua, teori ini adalah bagian dari uşul al-fiqh karena secara terperinci menjelaskan ilmu-ilmu yang dibutuhkan oleh hukum agama (fiqih) untuk menjelaskan ilmu-ilmu yang dibutuhkan oleh hukum agama (fiqih) untuk menarik kesimpulan secara metodis (istinbât. ). Teori ini juga menjelaskan pengaruh asumsi implisit dan eksplisit faqîh mengenai bentuk dan proses mengeluarkan fatwa agama dan pemahaman yurisprudensi. Di samping itu, teori ini menjelaskan anggapan tentang konsep "teks yang jelas" (žâhîr) dan alasan mengapa putusan khusus mensyaratkan adanya putusan umum dan tingkat pengaruh teologi (kalam) pada hukum agama (fiqh). Ketiga, teori ini adalah bagian dari irfân sebab teori ini menjelaskan sharî‘ah, tarekat dan haqiqah sebagai tiga aspek agama yang masing-masing pantas menjadi satu bidang khusus dan mewarisi perspektif yang unik. Oleh karena itu, rahasia perselisihan abadi para filsuf, fuqaha dan sufi dapat dijelaskan: mereka telah memperselisihkan interpretasi yang berbeda atas tiga dimensi agama tersebut yang telah muncul karena pengalaman dan tradisi yang berbeda. Sebab itu, teori ini menjelaskan makna dari syair berikut:

The difference among Moslems, Zoroastrians, and Jews

Emanate, O learned one, from their various points of views. ${ }^{58}$

Adakalanya kelahiran teori Soroush itu dipengaruhi oleh perilaku agamawan Islam yang menurut Soroush melakukan tindakan kurang tepat dalam beragama hingga tidak mendatangkan keuntungan apapun dan bahkan sebaliknya, membahayakan 'Islam'. Tindakan-tindakan kurang tepat tersebut antara lain ekstremisme Islam dan sebagian

\footnotetext{
${ }^{56}$ Hashas, “Abdolkarim Soroush”, 150.

57 Marco Demichelis, "New-Mu'tazilite Theology in the Contemporary Age: The Relationship Between Reason, History and Tradition", Oriente Moderno, Vol. 90, No. 2 (2010), 420.

58 Soroush, Reason, 35.
} 
kaum Muslim yang gemar melakukan hubungan oportunistik dengan Barat. Dua kubu tersebut merupakan dua posisi yang sama-sama tidak dikehendaki Soroush meskipun untuk tidak menjadi bagian dari salah satunya adalah pekerjaan yang sulit. Kebanyakan Muslim pada saat ini masih terjebak dalam lingkaran kedua model keberagamaan tersebut. Soroush mengungkapkan bahwa ada orang-orang yang, dengan dalih menjaga kemurnian agama menegasikan bantuan teman maupun musuh. Kemudian ada juga orang-orang yang karena ingin menjadikan agama multiguna dan kuat bergabung dengan sekutu dan pihak asing. Upaya yang pertama mengakibatkan isolasi dan kakunya agama (tahajjur), sedangkan upaya yang kedua melahirkan koalisi oportunistik dan tidak harmonis. Upaya yang ditujukan untuk menghindar dari dua bahaya kembar itu sama dengan menapaki suatu jalan yang lebih sempit daripada sehelai rambut dan lebih tajam daripada mata pedang. Tidak ada musafir yang mau menjalani jalan seperti itu, selain musafir yang cekatan. Selain memecahkan masalah di bidang teologi (kalâm), teori penyusutan dan pengembangan (qabd wa bast) aktif bekerja pada isu-isu epistemologi. Kita harapkan para pengkaji dan mereka yang menyenangi bidang ini akan mendapatkan manfaat juga dari aspek teori ini di bagian ini. ${ }^{59}$

Soroush juga mengungkapkan bahwa ada sebagian orang yang mengaburkan antara agama dengan dunia. Orang-orang yang menganggap agama sebagai fana karena menurut mereka agama dan dunia berbahasa yang sama. Dalam hal ini Soroush menjelaskan bahwa ada orang-orang yang bertanya, seandainya agama memang terbukti fana, mengapa kita masih membutuhkannya? Mengapa kalau begitu, kita tidak memfokuskan perhatian kita pada masalah zaman kita secara bersama-sama? Akar angan-angan ini adalah keyakinan bahwa dunia dan agama berbahasa yang sama. Akan tetapi hal yang sebenarnya adalah bahwa kultur temporer tidak bisa menjadi pengganti agama, tetapi hanya sebuah alat untuk memahami pesannya. Kedua hal itu sama sekali berbeda. Sekiranya al-Qur'ân dan Sunnah menerima interpretasi apa saja (yang memang tidak demikian), dapatkah kita mencari jawaban dalam setiap ajaran apa saja?. ${ }^{60}$

Perluasan yang dimaksud Soroush bukanlah bermakna bahwa ilmu pengetahuan buatan manusia dimaksudkan untuk mengganti agama, tidak juga penyempitan dimaksudkan untuk menjadikan agama

\footnotetext{
${ }^{59}$ Ibid., 35-36.

${ }^{60}$ Soroush, Reason, 36.
} 
sebagai memiliki peran kelas dua terhadap ilmu pengetahuan. Sebaliknya, yang dia maksudkan adalah bahwa kumpulan pengetahuan yang telah diakumulasikan oleh akal manusia mesti menjadi pembimbing di dalam menyempurnakan dan mengembangkan pemahaman manusia terhadap agama. ${ }^{61}$

Hubungan antara agama dan dunia bagi sebagian orang bisa jadi sangat erat. Agama bisa berfungsi untuk menjelaskan dunia sehingga dapat memberikan peringatan dan menghindarkan manusia dari kerusakan dan kehancuran. Sebaliknya, dunia dapat berfungsi menjelaskan agama karena perkembangan ilmu pengetahuan teknologi dapat menjadi sebuah media untuk menjelaskan maksud-maksud firman Allah di dalam wahyu-Nya. Dengan demikian, bukannya kebudayaan dan tren kontemporer yang serba berubah itu yang dijadikan pedoman kehidupan akan tetapi agama itulah yang tetap menjadi tujuan dan way of life bagi manusia sejagad meski ia hidup dalam berbagai jaman yang berbeda-beda.

\section{Penutup}

Klaim otoritas kebenaran agama lahir karena pemilik pemahaman keagamaan tidak membangun sebuah kesadaran bahwa pemahaman keagamaan mereka hanya merupakan salah satu dari pemahaman keagamaan yang lain dan hal itu tidak bersifat sakral. Soroush menekankan seharusnya yang memiliki otoritas tertinggi adalah agama dan bukan pemahaman keagamaan. Pemahaman keagamaan hanya merupakan ijtihad dari para mufassir atau pemikir untuk menemukan makna-makna dari teks-teks keagamaan. Ideologisasi agama dapat menurunkan nilai kesakralan dan keilahian agama menjadi bersifat duniawi, manusiawi, dan hilang kesakralannya. Lebih bahaya lagi ideologisasi agama dapat melahirkan tirani dan otoritarianisme atas nama agama. Kesadaran pluralitas pemikiran menjadi sangat penting untuk menghindari lahirnya otoritarianisme pemahaman keagamaan, dan ia dapat menjadi pilar-pilar demokrasi bagi sebuah pemerintahan.

\section{Daftar Rujukan}

Amirpur, Katajun dan Tavassoli, Sasan. "Christian Encounters with Iran: Engaging Muslim Thinkers after the Revolution (Review)", International Journal of Middle East Studies, Vol. 44, No. 3, 2012.

Andresen, Joshua. "Deconstruction, Secularism, and Islam", Philosophy Today, Vol. 56, No. 4, 2012.

${ }^{61}$ Bagir, "Kata Pengantar", xxv. 
Ashraf, Ahmad dan Banuazizi, Ali. "Iran' Tortuous Path toward "Islamic Liberalism", Journal of Politics, Culture, and Society, Vol. 15, No. 2, 2001.

Bagir, Haidar. "Kata Pengantar: Soroush: Potret Seorang Muslim "Liberal" dalam Abdul Karim Soroush, Menggugat Otoritas dan Tradisi Agama, Mahmoud Sadri dan Ahmad Sadri (eds.), terj. Abdullah Ali. Bandung: Mizan, 2002.

Bernaz, Nadia. "Life Imprisonment and the Prohibition of Inhuman Punishments in International Human Rights Law: Moving the Agenda Forward", Human Rights Quarterly, Vol. 35, No. 2, 2013.

Boroujerdi, Mehrzad. "Comparative Politic (review)", Perspectives on Politics, Vol. 9, No. 3, 2011.

Boroumand, Ladan dan Boroumand, Roya. "Illusion and Reality of Civil Society in Iran: An Ideological Debate", Social Research, Vol. 67, No. 2, 2000.

Brumberg, Daniel. "Dissonant Politics in Iran and Indonesia", Political Science Quarterly, Vol. 116, No. 3, 2001.

Chehabi, H. E. "Eighteen Years Later: Assessing the Islamic Republic of Iran", Harvard International Review, Vol. 19, No. 2, 1997.

Demichelis, Marco. "New-Mu'tazilite Theology in the Contemporary Age: The Relationship between Reason, History and Tradition", Oriente Moderno, Vol. 90, No. 2, 2010.

Foody, Kathleen. "Behrooz Ghamari-Tabrizi, Islam and Dissent in Postrevolutionary Iran: Abdolkarim Soroush, Religious Politics and Democratic Reform", Contemporary Islam, Vol. 6, No. 2, 2012.

Gulen, M. Fethullah. The Essentials of the Islamic Faith. t.t.: Feedsbooks, 2005.

Harris, Kevan. "Democracy in Iran (Review)", Middle East Journal, Vol. 64, No. 4, 2010.

Hashas, Mohammed. "Abdolkarim Soroush: The Neo-Mu'tazilite that Buries Classical Islamic Political Theology in Defence of Religious Democracy and Pluralism", Studia Islamica, Vol. 109, No. 1, 2014.

Heyking, John Von. "Mysticism in Contemporary Islamic Political Thought: Orhan Pamuk and Abdolkarim Soroush", Humanitas, Vol. 19, No. 1, 2006.

Hollenbach, David. "Comparative Ethics, Islam, and Human Rights: Internal Pluralism and the Possible Development of Tradition", Journal of Religious Ethics, Vol. 38, No. 3, 2010. 
Jahanbakhsh, Forough. Islam, Democracy, and Religious Modernism in Iran 1953-2000: from Bazargan to Soroush. Leiden: Brill, 2001.

Joffé, George. "At the Turning Point". The World Today, Vol. 55, No. 4, 1999.

Kabir, Shah M. Nister Jahan. "Islam, Democracy, and The Question of Coexistence", Islam and Civilisational Renewal, Vol. 2, No. 3, 2011.

Kurzman, Charles. "Critics within: Islamic Scholars' Protests against the Islamic State in Iran", International Journal of Politics, Culture, and Society, Vol. 15, No. 2, 2001.

Lawrence, Bruce B. "Muslim Ethics: Emerging Vistas (Review)", International Journal of Middle East Studies, Vol. 38, No. 1, 2006.

Malik, Mustafa. "No god but God: The Origins, Evolution, and Future of Islam", Middle East Policy, Vol. 12, No. 2, 2005.

Mavani, Hamid. "Khomeini's Concept of Governance of the Jurisconsult (Wilayat al-Faqih) Revisited: The Aftermath of Iran's 2009 Presidential Election", The Middle East Journal, Vol. 67 No. 2, 2013.

Monshipouri, Mahmood. "Religion and Politics in Modern Iran: A Reader (Review)", Middle East Studies Association Bulletin, Vol. 40, No. 2, 2006.

Oh, Irene. "On Democracy, Violence, and the Promise of Islam", Journal of Church and State, Vol. 53, No. 1, 2011.

Pak-Shiraz, Nacim. "Filmic Discourses on the Role of the Clergy in Iran", British Journal of Middle Eastern Studies, Vol. 34, No. 3, 2007.

Shahrouri, Nahla. "Does a Link Exist Between Democracy and Terrorism?", International Journal on World Peace, Vol. 27, No. 4, 2010.

Soroush, Abdolkarim. "The Crust and the Core of Rule by the People" dalam http://drsoroush.com/en/the-crust-and-the-core-of-ruleby-the-people/diakses 17 Desember 2015.

----. Reason, Freedom, and Democracy in Islam Essential Writings of 'Abdolkarim Soroush. Oxford: Oxford University Press, 2000.

-----. The Expansion of Prophetic Experience: Essays on Historicity, Contingency and Plurality in Religion. Leiden: Brill, 2009.

Strindberg, Anders dan Wärn, Mats. "Realities of Resistance: Hizballah, The Palestinian Rejectionists, and al-Qaida Compared", Journal of Palestine Studies, Vol. 34, No. 3, 2005. 
Vakili, Valla. "Abdolkarim Soroush and Critical Discourse in Iran", dalam John L. Esposito and John O. Voll, Makers of Contemporary Islam. New York: Oxford University Press, 2001.

Wright, Robin. "Iran's Greatest Political Challenge", World Policy Journal, Vol. 14, No. 1, 1997. 